\title{
Understanding Good Practice in Workplace Coaching
}

\author{
Dimitra Skoumpopoulou \\ Newcastle Business School, Faculty of Business and Law, Northumbria University, UK \\ Email: d.skoumpopoulou@northumbria.ac.uk
}

\begin{abstract}
Workplace coaching is growing rapidly and many organisations use it as a way to motivate and support their employees in their careers. This paper is a theoretical paper that draws upon the authors' experiences of workplace coaching. The author discusses the main aspects of successful workplace coaching while it summarises the most important behaviours and attitudes of an effective workplace coach.
\end{abstract}

Keywords: Workplace coaching, coaching reflections, lessons learnt

\section{Introduction}

Nowadays the main aim for most organisations is to grow and expand. However, identifying and developing the leadership capacity to achieve this has proven for many a challenging task [1] and [2]. Since the traditional management development/training does not always deliver the desired results, organisations often use coaching as a way to develop self-confidence, self-efficacy, and contribute to actions that create results [3], [4], [5] and [2]. The reason behind this trend is possibly the fact that coaching is about helping other people to improve performance not by telling them what to do but by enabling them to learn how to change.

Coaching is a well-established practice that researchers have defined in different ways. For the Institute of Human Development coaching "involves, conducting a purposeful conversation, focused on one or more challenges or outcomes, stimulated by insightful and probing questions - rather than directly offering answers and solutions". According to [6] coaching "is a one-to-one learning and development intervention that uses a collaborative, reflective, goal-focused relationship to achieve professional outcomes that are valued by the coachee" [6:137]. From a slightly different perspective [2] suggest that "coaching is a training process that can develop self-confidence, self-efficacy, and contribute to actions that create results. Coaching is about helping other people to succeed" [2:18].

From a different angle coaching is a term often related to the sports industry. Athletes often pay astronomical wages to the best individuals in their field to coach them. In most of these cases the coach does not manage them or tell them what to do but rather the coach's job is "to get the best out of them" by transforming physical and psychological strengths into competency [7] and [2]. The coach's job is to support, guide and motivate the coachee to gain a better understanding of oneself in order to enable them to reach the peak of their capabilities [8] and [9]. We can apply this same philosophy in workplace coaching and thus summarise that workplace coaching can help an individual to realise their strengths and weaknesses while enabling them to find the answer to what works better for them rather than giving them the answers ready on the plate. After all coaching is about unlocking people's potential with the intention to improve/maximize their performance; a coach does not teach but rather helps the coachee to learn [10].

Coaching can be a challenging endeavor for the coachee as well as the coach. It is essential for the coach to have a clear understanding of his/her role and responsibilities as well as being equipped with the desired behaviors and characteristics that can enable all parties involved to gain the best experience from the coaching sessions [11], [12] and [13]. The main aim of this paper is to gain an understanding of good practices in working place coaching.

\section{Good Practices in Workplace Coaching}

This section reviews various aspects of effective workplace coaching and it starts with understanding 
workplace coaching. It also discusses the process of effective workplace coaching while it concludes with various difficulties that can arise during workplace coaching and provides some suggestions on how to overcome them.

\subsection{Understanding Workplace Coaching}

Coaching can help coachees to develop themselves in such a way that benefits them as well as their organisation by focusing on results and how to get these results [14] and [15]. According to [16] coaching in the workplace can empower individuals and encourage them to be more motivated and committed to what they are doing. These can be extremely beneficial for the organisation since it means that their employees are motivated, exhibit strong performances and are happy with their jobs. Consequently, there will be greater productivity and self-reliance amongst employees, with less need for regular supervision by management [17] and [18].

Coaching others is a very serious responsibility because a coach can impact (often influence) their coachees intellectually as well as emotionally. However, it is important to remember that a coach is neither an expert nor a mentor but rather someone who manages to show the coachee the way to explore their own experiences and resources and facilitates them to generate their own solutions and answers [19], [20] and [21]. The relationship between the coach and the coachee is the basis upon which the coaching is built and without a relationship the coaching would not be as effective as it could be [8]. Therefore, trust and transparency are two very important factors that can help to create a good coaching relationship. Coachees might feel uncertain or skeptical about coaching and therefore a coach's approach and manner should help ease the coachees concerns and make them feel comfortable in the coaching situation within a short space of time. If they feel comfortable then they will be willing to engage and continue with the coaching which could help them gain the desired outcomes [20], [22], [23] and [24].

Additionally, the coach needs to be effective in understanding both the organisation as well as the coachee in order to be able to comprehend the situation and support the coachee in the best way possible [25].

A coach must be able to form a strong relationship, follow a clear coaching methodology/structure as well as being ethical [26] and [8]. Ethics in coaching is concerned with morality which in simple terms distinguishes what is right from wrong [27] and [28]. Coaches have a duty to manage confidentiality during their coaching sessions because their role involves building relationships and often they can influence the coachees which consequently increases the importance of ethical coaching. According to [27] a coach should be able to know where to draw the line in order to abstain from taking advantage of situations and they need to be consistent so coachees can have confidence in them which subsequently will result in a trustworthy relationship. Exceptions to confidentiality relate to circumstances where there is an intent to seriously cause harm to someone, child abuse and other safeguarding concerns.

\subsection{Understanding the Process of Effective Workplace Coaching}

Workplace coaching can be a challenging task not only for the coach but also for the coachee. Coaching in a business setting is about supporting and providing feedback, advice and guidance to individuals in an effort to help them improve their personal effectiveness in their organisations [29]. Often, the coachees might not know what to expect, they might not have clear objectives or outcomes that they want to discuss or they might overall feel a bit apprehensive to discuss personal feelings, thoughts and ideas [30]. Therefore, the coach needs to be prepared and able to keep the session alive/going no matter what the circumstances. Various models can enable the coach and coachee to start a conversation and aid the coach to keep a structured approach during the coaching session [31] and [32]. This structured approach can be helpful for the coach since he/she will know how to proceed regardless of the situation but also could help the coachee to open up more and speak more freely [33] and [34]. Most of these models start with establishing rapport and they usually close the session with some sort of summary of what was discussed and the main objectives/goals/outcomes that need to be achieved or have been achieved. A typical coaching session should include aspects such as the ones shown/discussed in Table 1. 
Table 1: Suggested framework for coaching conversations

\begin{tabular}{ll}
\hline Establish Rapport & Make the coachee feel comfortable e.g. ask some basic everyday questions. \\
& Establish what the coachee expects from the session. \\
Agree timings, outline and agree boundaries, explain to coachee if any of the \\
discussions will be reported back to managers etc.
\end{tabular}

A general rule to remember (although not always possible) is to avoid any "Why" questions because they can be perceived as judgemental.

Finally, keeping effective records of coaching sessions can be an invaluable resource that can help a coach to have a clear picture of the coachees development, change, successes and achievements what [35] and [36]. Maintaining records of what was discussed and thoughts/ideas the coachee has shared with the coach can enable the coach to possibly observe and identify recurring issues and themes that need addressing as well as being used as a reminder of how the coachee has been developing over time. Note taking can also aid the coach in the effort to identify and agree appropriate goals and objectives, which all parties can revisit during the course of coaching sessions. Sometimes keeping notes can help because it provides breaks in the flow of the session which can give both parties time to reflect on the themes already discussed, to be discussed or questions to be asked [37] and [38].

\subsection{Difficulties Arising during Workplace Coaching and How to Overcome Them}

One of the most important aspects for effective coaching is the relationship that a coach and a coachee can develop through the coaching sessions. However, there can be a number of barriers that can jeopardise this relationship [39] and [40]. As [27] suggests coaching does not happen in a vacuum, but usually takes place in a working environment where all sorts of barriers can arise. These barriers can be organisational as well as individual/personal [41] and [42]. The question perhaps remains how we can make workplace coaching really work effectively for all parties involved. Table 2 summarises various organisational as well as individual barriers to coaching while it also suggests strategies for overcoming them.

Table 2: Barriers and possible solutions

\begin{tabular}{ll}
\hline Organisational Barriers & $\begin{array}{l}\text { Strategies of overcoming organisational and } \\
\text { individual barriers }\end{array}$ \\
\hline Lack of time and support - the organisation is & It is essential to understand that many of these barriers \\
pre-occupied with other issues and cannot see the & are things that people perceive because they do not know \\
importance/benefits of coaching for its employees & what coaching might really mean. These fears and \\
Fear of employees and/or of the coach - & insecurities often exist because managers and employees \\
where the organisation is afraid/worried to either & are worried about the unknown and they do not know \\
upset the employees because they do not know & what to expect. Therefore, if people are properly educated \\
their reactions or they are worried that coaches & about coaching and how it could benefit them, their \\
might be a risk to the management style/position & attitude might change. \\
\hline
\end{tabular}


Fear of risk - worried about the cost involved and how it will be implemented Unwillingness to recognise difficult performance issues - managers push employees to think and work quickly and fail to realise that they should see things from a different perspective

\section{Individual Barriers}

Poor personal relationship with the coach it is important to find a coach that the coachee feels comfortable with

Fear of failure - some coachees might not know how to learn to do something different and they might worry that they will do it wrong

Fear of extra work - the coachee might be reluctant of coaching if he/she thinks/feels that it might be on top of their current duties and responsibilities

Fear of appearing incompetent - it is more difficult to hide personal weaknesses in one-to-one situations and coachees might worry that their shortcomings will be revealed. However, we need to always remember that nobody is perfect and it is up to us to take our weaknesses and make them strengths

Fear of change - people often fear the unknown and they do not like to get outside their comfort
It is important for all parties involved to realise that time spent in coaching is still time when work is being done and it should not be seen as an extra duty or responsibility. Emphasise that coaching leads directly to change and improvement and it is strongly linked with the actual outcomes and objectives of the organisation.

Coaches need to work on creating effective relationships with their coachees by using the various tools and techniques; they will ask questions, listen carefully, make the coachee feel that they are the centre of the attention and in that way the coachee will feel valued, relaxed and confident.

Ensure that all parties involved are aware of the benefits that can be gained from coaching and introducing this new concept in an encouraging and supportive environment.

Start from what people can currently do and build on that. Give people confidence in their own skills and performance by using positive feedback; this can give them greater satisfaction and confidence in their ability to learn and improve.

This section attempted to gain a better understanding on the workplace coaching practice as well as considered the processes involved for effective workplace coaching. The next part discusses the author's reflections from her own coaching experiences.

\section{Undertaking Workplace Coaching - Reflecting on Coaching Experiences}

\subsection{The Coaching Process - Getting Them Talking}

A coach must recognise that every coachee is a unique individual (and should be seen as such) and therefore although one approach might be appropriate for one coachee however, the same approach might not be as effective for another. Thus a coach needs to be flexible in their approaches and adaptable to various situations that might arise in different sessions.

For example, various techniques and tools can be used during coaching sessions. Some useful tools and techniques are the SWOT analysis, leadership attributes, coaching wheel, things you are proud about in your career, what if scenarios and so on. However, it is important to remember that tools and techniques can be effective but their successful application can depend on the situation.

The SWOT analysis although it has a limited scope in just identifying strengths, weaknesses, opportunities and threats in a personality when we all know how complicated someone's personality can be, however, the SWOT analysis is an excellent tool to start the coaching sessions especially the first coaching session with various clients. It can be a good ice breaker during the first sessions and it can enable the coach to get an initial idea of the extent that a client has a clear self-awareness. This can be very helpful since it can enable the coach to decide the best way to approach clients during sessions. Also, by identifying weaknesses and threats they can a good starting point of identifying some potential 
issues to cover in the sessions to follow. However, in some occasions this might not work and therefore the coach needs to be prepared to be adaptable.

Additionally, asking a client to tell you 2-3 things that they feel proud of in their career can be really beneficial, especially if the client is not very positive towards coaching. By asking them to discuss positive things regarding their career often will make them less guarded, less negative or suspicious about coaching. This can make them feel more comfortable which would consequently mean that they will be happier to talk and engage in the process. However, the coach should also keep in mind that they have to challenge the coachee rather than just leave them in their comfort zone to talk about the things that they are doing well. Follow up questions that challenge the coachee can be equally important. Such questions can be for example: How did you achieve success in these 2-3 things and how can you use what you learnt now? How can you make the situation you are facing now also a success?

Another useful tool is the coaching wheel which enables coachees to identify some competencies that they need in order to be effective and efficient in their role. This is an effective approach for those cases that they know what they need to work on and they just need a bit of motivation and guidance in achieving it. Similarly, the leadership attributes can be a good starting point in those cases that they wanted to progress and by looking at each attribute it can help the client to identify what they need to develop in order to be able to progress in their role and organisation. Although the leadership attributes are very useful and they can encourage rich conversation they can have a limited scope especially in dealing with some cases where clients face various issues and problems at work.

Some cases are more difficult than others but there is always a way to get the client talking, as long as the coach himself/herself is prepared to get out of their own comfort zone and try different techniques. The one thing that often works is if you ask the right question at the right time to the right person. Emotional intelligence is a very important factor in making a session successful. The coach needs to know/feel/understand when they should ask certain questions and how. The same question might cause a lot of tensions the one day and bring a completely different reaction from the same client on a different day. The coach needs to be alert in getting these hints and act appropriately no matter how difficult this may be.

\subsection{The Coaching Process - Setting Learning Goals}

It is important to clarify expectations from the outset and therefore asking the coachee "what do you want to achieve out of these sessions" can be a very useful aspect in establishing the success of the coaching process. This would help the client to think where they are now in comparison to where they want to be. How can they get to the desired place and what do they need to do in order to get there? This would then enable them to identify what goals they want to set which will help them in achieving their ultimate goal/objective.

Once the coachee identifies what they want to achieve then it would be a natural progression to try to think of actions that he/she needs to take in order to achieve the main outcome. The main difficulty is when the coachee does not know what they want to achieve or where they wanted to be.

A useful line of inquiry is to ask questions such as how do you feel about your work right now, what would you like to focus on, how can you use your strengths, what help/support do you need and so on. This line of questioning can help the coachee to consider different perspectives and options that they did not consider before. The intention is not to draw their attention to the negative parts of their work but to help them understand their abilities and competencies which they could use and explore further in their role.

A main objective for the coach is to ensure that the goals set are specific, measurable, achievable, realistic and timed (SMART). This can enable the coachee to build their confidence and achieve their goals which consequently would encourage them to continue rather than set goals that are too ambitious and over optimistic which could potentially lead to failure and disappointment.

\subsection{Coaching Process - Active Listening}

One of the most important parts of coaching is active listening. This requires the full attention of the coach first because he/she needs to be prepared to ask appropriate and relevant questions and second because he/she must make an effort to ensure that the coachee feels comfortable and motivated to talk 
about their issues, feelings, problems and so on. Maintaining good eye contact while using friendly gestures and facial expressions can be a basic rule. Encourage the client to continue talking and open up by using encouraging words such as "that is interesting", "good idea", "well done" and so on. If the coachee pauses do not feel that you have to fill in the silence, let them find their own pace and give them time to structure their thoughts and speech. One of the things that can be very helpful and effective is taking notes while the client is talking and then at the end try to repeat these to the coachee. That way first you can make sure that you have been keeping accurate records, second you have the opportunity to clarify aspects that might not have been clear and of course thirdly you can show them in that way that you were listening to them and taking them seriously. Active listening is also demonstrated with the appropriate use of questioning techniques. For example, by using open questions and questions that are non-judgemental.

Questioning technique is another very important aspect of effective workplace coaching. For example, open questions starting with "How" or "What" are one of the most common ones used. They are complimentary and they can help make the coachee feel comfortable in talking about things rather than feeling guilty around problems or issues. Sometimes probing questions are proven to be very useful in clarifying things or even using them for the purpose of helping the coachee explain something themselves rather than you pointing it out, e.g. "how did you go about doing this or that?" Finally, try to use reflective questions such as "you feel sad about this, what makes you sad?", "you seem to have done a good job there, what do you think made it a success?" These types of questions can help the coach to gather more information for a specific incident as well as enabling them to encourage/lead the coachee to focus on these aspects that they are feeling comfortable with.

\subsection{The Coaching Process - Keeping Appropriate Records}

Record keeping in coaching is very important because it helps predominantly the coach, but assists the coachee as well, to keep track of the conversations they have, the goals they set, the actions they are committed to complete and so on. This means that there is continuity between the sessions and that way the coachee and coach can have a clearer idea of what was discussed and agreed and then decide what the best way forward; so that the client can take away the maximum possible advantages.

Record keeping helps with the appropriate planning of the sessions since the coach can have a record of what works and what does not. On top of that the notes taken can be used for the purposes of assessing the coaching situations as well as to evaluating the progress of the coachees.

In some cases, the coach may have to provide a record of what is happening in the coaching sessions and therefore the record keeping enables the coach to offer a clear, complete and up to date log of what is discussed, the evaluation of the situation and measure the progress made, as well as offer clear suggestions of what possibly is needed for the future.

Furthermore, by keeping notes the coach could go back to them in order to evaluate the various tools, techniques and approaches used during the sessions and that way the coach can review and reflect on what is working in each situation. This also means that they could create a list of what is the best way of approaching a situation, something that can also be used in future cases/clients. Finally, this record keeping is not only a way to evaluate the coachee but can also been used for helping the coach to realise their own development needs and shortcomings.

\section{Conclusions - Lessons Learnt}

It is important to understand that there is no right or wrong answer and that different people have different backgrounds and experiences, different values and expectations and rather than judging them a coach needs to learn how to cope with them and how to deal with them. Sometimes when there is a perceived weakness in a person you can use that weakness to create a success. For example, if you are dealing with a person who changes his/her mind all the time, rather than look into this as a disadvantage for that person, why not view this from the perspective that this person is creative. 
Table 3: Behaviours and characteristics of an effective workplace coach

\begin{abstract}
Maintain good rapport - Understanding the coachee is very important in order for them to feel comfortable and content during the coaching sessions. By being open, friendly and approachable the coach can win over the coachee and help them to open up and share their personal experiences.

Challenging - Asking the right questions in order to help the coachee to discover the answer(s) that they are looking for. This way the coachee can use their own resources to achieve the desire outcomes. A good coach can inspire and stimulate the coachees thoughts on how to improve, change or try something different. They will encourage the coachee to try new things/behaviours rather than stick on old ways that might not be working anymore.
\end{abstract}

Maintain Confidentiality - This is very important because it can make the coachee feeling safe, secure and will help in encouraging them to open up and share any issues, feelings and personal situations that might be critical for their development. If they feel that the coach is trustworthy and honest it is most likely that they will actively engage in the coaching session.

Non-judgemental - A good coach does not highlight mistakes and errors but rather encourages the coachee to think about situations and analyse them, themselves. For example, rather than saying this or that is wrong a good coach could ask "How do you feel that went?" allowing the coachee to participate in a dialogue and therefore any feedback/advise becomes more eloquent.

Encouraging/Assertive - A good coach needs to be positive and constructive towards their coachees. However, it is also important to know when to stop or even give up if necessary. A good coach makes sure that they provide their coachee with a clear message and they do not give diluted feedback. For example, they will not say "you did well but...".

Objective - A good coach must be independent - not taking sides. Also, he/she must be able to base their feedback/comments on clear information that is pre-determined or pre-discussed rather than on how he/she feels at the moment. This makes the feedback meaningful and relevant for the coachee to apply.

Empathetic - A good coach is a good listener and they remember to look at things from the coachee's point of view rather than just trying to force their own views and opinions.

Supportive - A good coach understands that some people adjust more quickly than others and keeps this in mind. By being supportive and patient it can allow the coachee to take his/her time to modify their behaviour without discouraging them by being too critical.

Observant - In order to understand the coachee and their personality this can help the coach to adjust towards what the coachee needs. Understanding the personality and behaviour of the individual can often be critical in making the coaching to be effective. For example, an amiable individual might need to be handled in a more sensitive way while a more direct coachee can be treated in a more forward manner.

Knowledgeable/skilled - A good coach needs to be organised and clear on what needs to be achieved. A good coach should be consistent, sending clear messages that do not confuse the coachee with what they might think or feel at the time. They should have a good knowledge of the skills and techniques and how they can use them appropriately in order to help coachees to achieve their required objectives/outcomes/results.

Table 3 summarises the main lessons learnt and highlights the main behaviours and characteristics of an effective workplace coach. When engaging in coaching it is very important to consider carefully the various tools and techniques that a coach can use in order to question and communicate with clients. This is so important that often the way a coach might express himself/herself can make or break a coaching relationship. Using questions like "Why did you do that? Why did you not do that?" is often perceived as being very judgemental and often can make the coachee to shut down and stop engaging. On the other hand, questions like "How can you do this differently? How do you feel about this? How did this situation make you feel? What can you do about this?" can very often make people look at things from different angles and sometimes they can get to see things from a different perspective without the need to force them into it, they make that discovery for themselves. Sometimes the solution can be in front of us for a very long time and we cannot see it; but it takes just a few seconds and the right motivation to finally realise it and change things for the better. 


\section{References}

1. B.J. Avolio, Full Range Leadership Development,Sage Publications, Los Angeles, CA 2011.

2. M. E. Berg and J. T. Karlsen, "An evaluation of management training and coaching", Journal of Workplace Learning, Vol. 24 no. 3, pp. 177 - 199, 2012.

3. D. C. Feldman and M.J. Lankau, "Executive Coaching: a review and agenda for future research", Journal of Management, vol. 31, no. 6, pp. 829-848, 2005.

4. E. Cox, T. Bachkirova and D. Clutterbuck, The complete handbook of coaching, London: Sage, 2010.

5. J. Passmore and A. Fillery-Travis, "A critical review of executive coaching research: a decade of progress and what's to come", Coaching: An International Journal of Theory, Research and Practice, vol. 4, no. 2, pp. 70-88, 2011.

6. J. W. Smither, "Can psychotherapy research serve as a guide for research about executive coaching? An agenda for the next decade", Journal of Business Psychology, vol. 26, pp. 135-145, 2011.

7. K. K. Miller and W. Hart, Choosing an executive coach, Greensboro, NC: CCL Press, 2001.

8. L. Baron and L. Morin, "The coach-coachee relationship in executive coaching: a field study", Human Resource Development Quarterly, Vol. 20, no. 1, pp. 85-106, 2009.

9. L. Boyce, J. Jackson, and L. J. Neal, "Building successful leadership coaching relationships: Examining impact of matching criteria in a leadership coaching program", Journal of Management Development, vol. 29 no. 10, pp. 914-931, 2010.

10.J. Niemes, "Discovering the values of executive coaching as a business transformational tool", Journal of Organizational Excellence, vol. 21, pp. 61-69, 2002.

11.S. Graham, J. Wedman and B. Garvin-Kester, "Manager coaching skills: What makes a good coach?"Performance Improvement Quarterly, vol. 7, no. 2, pp. 81-94, 1994.

12.A. Grant and D. Stober, "Introduction", In D. Stober \& A. Grant (Eds.), Evidence based coaching: Putting best practices to work for your clients (pp. 1-14). New Jersey, USA: Wiley \& Sons, 2006.

13.D. McKenna and S. Davis, "Hidden in plain sight: The active ingredients of executive coaching", Industrial and Organizational Psychology: An Exchange of Perspectives on Science and Practice, vol. 2, no. 3, pp. 224-260, 2009.

14.L. L. Tobias, "Coaching executives", Consulting Psychology Journal: Practice and Research, vol. 48, no. 2, pp. 87-95, 1996.

15.B. Palmer, "Maximizing value from executive coaching", Strategic HR Review, vol. 2, pp. 26-29, 2003.

16.M. Bernett, Practical Guide to Coaching in the Workplace, Available from: http://www.hrweb.co.uk/pdfs/Coaching.pdf (Accessed 29th of April 2016), 2009.

17.R. Wageman, "Critical success factors for creating superb self-managing teams", Organisational Dynamics, vol. 26, no. 1, pp. 49-61, 1997.

18.K.M. Wasylyshyn, "Executive coaching: An outcome study", Consulting Psychology Journal: Practice and Research, vol. 55, no. 2, pp. 94-106, 2003.

19.G. Olivero, K. D. Bane and R. E. Kopelman, "Executive coaching as a transfer of training tool: Effects on productivity in a public agency", Public Personnel Management, vol. 26, pp. 461-469, 1997.

20.J. McGovern, M. Lindemann, M. Vergara, S. Murphy, L. Barker and R. Warrenfeltz, "Maximizing the impact of executive coaching: Behavioral change, organizational outcomes, and return on investment", The Manchester Review, vol. 6,pp. 1-9, 2001.

21.J. C. Quick and M. Macik-Frey, "Behind the mask: Coaching through deep interpersonal communication", Consulting Psychology Journal: Practice and Research, vol. 56, pp. 67-74, 2004.

22.T. R. Bacon and K. I. Spear, Adaptive coaching: The art and practice of a client-centered approach to performance improvement, Palo Alto, CA: Davis-Black, 2003.

23.A. D. Ellinger, A. E. Ellinger and S. B. Keller, "Supervisory coaching behavior, employee satisfaction, and warehouse employee performance: A dyadic perspective in the distribution industry", Human Resource Development Quarterly, vol. 14, pp. 435-458, 2003.

24.E. Goldman, M. Wesner and O. Karnchanomai, "Reciprocal peer coaching: a critical contributor to implementing leadership plans", Human Resource Development Quarterly, vol. 24 no. 1, pp. 63-87, 2013.

25.P. Shaw and R. Linnecar, Business coaching: achieving Practical Results Through Effective Engagement, John Wiley \& Sons Ltd, 2007. 
26.K. Gyllensten and S. Palmer, "The coaching relationship: an interpretative phenomenological analysis", International Coaching Psychology Review, vol. 2, no. 2, pp. 168-177, 2007.

27.D. Pardey, Coaching, Published Burlington. MA: Butterworth-Heinemann, 2007.

28.M. Duff and J. Passmore, "Coaching ethics: A decision making model", International Coaching Psychology Review, vol. 5 no. 2, pp. 140-151, 2010.

29.R. Agarwal, C. Angst and M. Magni, "The performance impacts of coaching: A multilevel analysis using hierarchical linear modeling", International Journal of Human Resource Management, Vol. 20, no. 10, pp. 21102134,2009 .

30.S. Kim, T. Egan, W. Kim and J. Kim, "The impact of managerial coaching behaviour on employee work-related reactions", Journal of Business Psychology, vol. 28, no. 3, pp. 315-330, 2013.

31.K. J. Preacher and A. F. Hayes, "Asymptotic and resampling strategies for assessing and comparing indirect effects in multiple mediator models", Behavior Research Methods, vol. 40, pp. 879-891, 2008.

32.J. O. Burdett, "Forty things every manager should know about coaching", Journal of Management Development, vol. 17 no. 2, pp. 142-152, 1998.

33.G. N. McLean, B. Yang, M. H. C. Kuo, A. S. Tolbert and C. Larkin, "Development and initial validation of an instrument for measuring managerial coaching skill", Human Resource Development Quarterly, vol. 16, no. 2, pp. 157-178, 2005.

34.M. Hagen, "Black Belt coaching and project outcomes: An empirical investigation", Quality Management Journal, vol. 17, no. 2, pp. 54-67, 2010.

35.S. Graham, J. Wedman and B. Garvin-Kester, "Manager Coaching skills: development and application", Performance Improvement Quarterly, vol. 6, no. 1, pp. 2-13, 1993.

36.S. Persson, "Coaching as a tool for learning: An interplay between the individual and organizational level", Studies in the Education of Adults, vol. 39, no. 2, pp. 197-216, 2007.

37.B. Joo, "Executive coaching: a conceptual framework from an integrative review of practice and research", Human Resource Development Review, vol. 4, no. 4, pp. 462-488, 2005.

38.A. Gladeanan Effective Note taking for coaches, accessed 29th of April 2016 through http://www.cognitivebehaviouralcoachingworks.com/effective-note-taking-for-coaches/, 2015.

39.S. Berglas, "The very real dangers of executive coaching", Harvard Business Review, June, pp. 87-92, 2002.

40.W. H. Hodgetts, "Using executive coaching in organizations: What can go wrong (and how to prevent it)", In C. Fitzgerald \& J. Garvey Berger (Eds.), Executive coaching: Practices and perspectives. Palo Alto, CA: DaviesBlack, 2002.

41.B. Redshaw, "Do we really understand coaching: how can we make it work better?", Industrial and Commercial training, vol. 32, no. 3, pp. 106-108, 2000.

42.T. G. Crane and L. N. Patrick, The heart of coaching: Using transformational coaching to create a highperformance coaching culture (3rd ed.), San Diego, CA: FTA, 2007. 